\title{
Spatial Distribution of Rainfall with Elevation in Satluj River Basin: 1986- 2010, Himachal Pradesh, India
}

\author{
*Sandeep Kumar ${ }^{1}$ and Santosh ${ }^{2}$ \\ ${ }^{1}$ Department of Environment Studies, Panjab University, Chandigarh, India. \\ ${ }^{2}$ Department of Environmental Sciences, MDU, Rohtak (Haryana), India. \\ E-mail address: ssheoran84@gmail.com, ssheoran81@yahoo.co.in \\ ${ }^{*}$ Author of Correspondence: \\ Dr. Sandeep Kumar, \\ Department of Environment Studies, \\ Panjab University, Chandigarh-160014 (India). \\ E mail: - ssheoran81@yahoo.co.in \\ Phone: +918901288772
}

Keywords: GIS, DEM, Himalayas, Interpolation, Orographic effect, Precipitation, Satluj River Basin.

\begin{abstract}
The complex relationship between topography and precipitation in mountainous regions such as Himalayas is evident from the pattern of rainfall distribution. The variation in precipitation with altitude is controlled by mean height of clouds and decrease in water vapours with altitude. Spatially distributed measurements of precipitation have gained renewed interest in connection with climate change impact studies. Precipitation values are usually available from a limited number of gauge stations and their spatial estimates can be obtained by interpolation techniques such as Inverse Distance Weighted (IDW), Kriging and Spline. In the present study, precipitation-elevation relationship can be established using Digital Elevation Model (DEM) (Advanced Spaceborne Thermal Emission and Reflection Radiometer-ASTER, 30m resolution), Spline interpolation technique in Geographical Information System (GIS) environment and point data from various gauge stations spread over the Satluj River Basin. Changes of spatial distribution of precipitation with elevation show a distinct shift. Bhakra Dam $(5854.60 \mathrm{~mm})$ to Rampur $(4451.10 \mathrm{~mm})$, there is continuous variation in rainfall with increase in altitude. But beyond Rampur, variation is very high. Swarghat shows exceptional rainfall $(8031.76 \mathrm{~mm})$, may be due to position of mountains and their orographic effects. Maximum rainfall was observed in the lower Himalayas i.e. Shiwalik range. Negligible rainfall was observed beyond Kaza $(470 \mathrm{~mm})$, above the elevation of around $3756 \mathrm{~m}$. The general trend of rainfall exhibits that the lower and middle parts experience good rainfall whereas the upper part experiences less rainfall. Such spatial and temporal distribution of rainfall with elevation provides an important platform for hydrologic analysis, planning and management of water resources.
\end{abstract}

\section{INTRODUCTION}

Precipitation displays complex spatial variations in mountainous terrain. The complex relationship between topography and precipitation in mountainous regions is evident from the pattern of rainfall distribution. Spatial variability in precipitation is mainly due to three factors: elevation, continentality (proximity to sources of moisture) and the effects of rain shadows apart from other topographic factors like prevailing wind, orientation and slope of the mountains. In mountainous areas, orographic effects can create vastly different microclimates over small distances. In these regions, orography provides necessary uplift to the moisture laden currents striking against a mountain or chain of mountains which results in copious rainfall on the windward side of the mountains. 
The geographical distribution of rainfall depends on two main categories of factors: topographic factors and climatic factors. The first category includes elevation, mountain orientation, slope of mountain side, leeward and windward positions, and distance from source of moisture. The second one includes atmospheric conditions, storm types, seasonal patterns of wind speed and direction. Elevation is the most important one affecting both the quantity and distribution of precipitation, especially in the mountainous regions (Taher and Alshaikh, 1998). The influence of mountain barriers on precipitation distribution has been attracting the attention of scientists for a long time. Depending upon the relief of a mountain, there may be continuous increase in precipitation with altitude and it may begin to decrease above a particular elevation (Singh et al., 1995; Singh and Kumar, 1997b).

Spatially distributed measurements of precipitation have gained renewed interest in connection with climate change impact studies. Precipitation values are usually available from a limited number of gauge stations and their spatial estimates can be obtained by interpolation techniques. Spatial interpolation is the estimation of spatial data that represents the entire surface from a given set of point data. The variation in precipitation with altitude is controlled by mean height of clouds and decrease in water vapours with altitude. Thus, precipitation in mountains can decrease with altitude above a certain level. Rainfall depths generally vary with space and time and tend to increase with increasing elevations because of the orographic effects of mountainous terrain which causes the air to be lifted vertically, and the condensation occurs due to adiabatic cooling (Goovaerts, 2000). The entire circulation of water in a catchment basin is governed by the spatial and temporal distribution of rainfall (Bacchi and Kottegoda 1995). Such studies will assist in the realistic assessment of the water resources and flood potential of these regions.

The spatial interpolation of meteorological data aims at estimating the value of rainfall at a given site based on the observation at neighbouring stations. The hydrological processes can not be properly represented until the distribution of precipitation is known. Mountainous environments pose a special challenge to spatial interpolation because the measured data are sparse, often restricted to lower elevations. Detailed analysis of spatial distribution of precipitation is generally hampered by meager network of gauges and those that do exist are unable to represent properly. Among all the hydro-meteorological parameters, rainfall is most difficult to predict due to its inherent variability in time and space (Guenni and Hutchinson 1998), especially for a complex mountainous terrain. Interpolation approach for a given set of input data is especially true for areas such as mountainous regions where data collection is sparse and measurements for given variables may differ significantly even at relatively reduced spatial scales (Collins and Bolstad 1996). It has been estimated that with increasing level of global warming, regions receiving snowfall will increasingly receive precipitation in the form of rain (IPCC, 2001a) and for every $1^{\circ} \mathrm{C}$ increase in temperature, the snowline will rise by about $150 \mathrm{~m}$ (Schadler and Bruno, 2004).

Hill (1881) made a detailed study of distribution of rainfall in the northwest Himalayas and found that rainfall increases with elevation up to a height of about $1,200 \mathrm{~m}$ and thereafter it decreases as the elevation increases. Dhar and Rakhecha (1981) attempted to obtain a suitable relationship between mean monsoonal rainfall and elevation in the Central Himalayas (Nepal Himalayas). This study has shown that i) there exists no linear relationship between elevation and monsoon rainfall, ii) elevation and rainfall parameters can be best related by a polynomial of fourth degree, and iii) zones of maximum rainfall occur near the foothills and at an elevation of 2,000$2,400 \mathrm{~m}$. Beyond this elevation, rainfall decreases continuously as elevation increases until the great Himalayan range is reached. Higuchi et al. (1982) studied the rainfall characteristics during the monsoon season in the high mountain areas of Nepal Himalayas and reported that rainfall decreases with altitude in the range from 2,800 to $4,500 \mathrm{~m}$. 
In the monsoon season, rainfall increases with elevation up to a certain height and then starts decreasing. In general, monsoon rainfall is found to be dominant in the outer and middle Himalayas. It has been noted that monsoon rainfall contributes about $46 \%$ and $41 \%$ to the annual rainfall of outer and middle Himalayas, respectively. The role of orography in the middle Himalayas was found to be more pronounced for both rainfall and snowfall in comparison to other ranges of Himalayas. Variation of snowfall with elevation was more prominent in comparison to variation of rainfall. In the greater Himalayan range it is found that rainfall decreases exponentially with elevation and snowfall increases linearly. Rainfall becomes negligible at elevations beyond 4,000 m on the windward side of the greater Himalayan range (Singh et al., 1995).

The precipitation distribution with altitude for the Satluj and Beas Basins in the Western Himalayas was studied by Singh and Kumar (1997). Rainfall increases linearly with elevation for both the basins in the outer Himalayan range. The middle Himalayan range of Beas Basin has exceptionally heavy rainfall on the windward side. Different trends of rainfall variation with elevation are observed in different seasons in the middle Himalayan range with a linear increase in annual rainfall. Rainfall follows an exponential decreasing trend with altitude in the greater Himalayan range. Average annual rainfall decreases from the outer to greater Himalayas in the Satluj Basin. Quantitative estimation of the spatial distribution of rainfall is required for various purposes like water resource management, hydrologic modelling, flood forecasting, climate change studies, water balance computations, soil moisture modelling for crop production, irrigation scheduling etc. (Basistha et al., 2008).

Precipitation-elevation relationship can be established using DEM and point data from various gauge stations spread over river basin. The most common form for the representation of elevation data in digital format is the grid type of raster form. Digital Elevation Model (DEM) is a numerical representation of the spatial variation on the earth's surface which represents land-surface as a matrix of elevation values, implicitly located by their geographical co-ordinates (Garg, 1991). DEM is an ordered array of numbers that represent the spatial distribution of elevations above some arbitrary datum in the landscape (Moore et al., 1993). It is an inalienable component of the GIS and one of the important data used for geo-spatial analysis. Based on the DEM, various kinds of topographical variables, such as slope, aspect, curvature, drainage etc, can be computed.

There are at least two alternatives that can be used to address the problem of data availability. The first is to make the rain-gauge network sufficiently dense. This option is costly, making it unrealistic. The second alternative is to use numerical methods to estimate the spatial distribution of precipitation between gauges, and to provide synthetic data at all locations within catchment. Various approaches are therefore developed to improve the interpolation results by incorporation of the impact of topography on precipitation. In the mountainous basins, weather system interacts with topography which results in highly non-uniform precipitation. The spatial and temporal distribution of precipitation with elevation provides essential input for understanding the hydrological processes of a river. In the present study, attempts have been made to understand the precipitation distribution with elevation in the Satluj River Basin. Such studies are very important for planning and operation of water resources.

\section{STUDY AREA}

The Satluj River (Vedic name - Satudri and Sanskrit name - Shatadru), also known as the Langqên (Chinese) and Sutlej (Indian), is the principal and easternmost tributary of the Indus River system. The basin area falls in Lahaul \& Spiti, Kinnaur, Shimla, Kullu, Mandi, Solan and Bilaspur districts of Himachal Pradesh. The geographical limits of area lie between $30^{\circ} 45^{\prime} \mathrm{N}$ to $33^{\circ} 00^{\prime} \mathrm{N}$ latitudes and $76^{\circ} 15^{\prime} \mathrm{E}$ to $79^{\circ} 00^{\prime} \mathrm{E}$ longitudes in the western Himalayas (Figure 1). The total catchment area of Satluj River, from origin to Bhakra dam, is about $56,875 \mathrm{~km}^{2}$ (21,960 Sq. miles). The upper part of river basin is considerably wider than the lower one. In Himachal Pradesh, Satluj 
Basin has catchment area of $20,398 \mathrm{Km}^{2}$ which is $30.7 \%$ of the total catchment area of river systems (SCST \& E, 2006). Indian part of river up to Bhakra Dam is elongated in shape and covers the part of outer (Shiwalik range), middle (Dhauladhar range) and greater Himalayas (Zaskar range).

Satluj River originates from the southern slopes of Kailash Mountains i.e. from Rakas Lake, near the Mansarovar Lake as Longcchen Khabab River at an elevation of about 4,572 $\mathrm{m}$ (15,000 ft), above msl. Total length of river is approximately $1,448 \mathrm{~km}(320 \mathrm{Km}$ in China, $758 \mathrm{Km}$ in India and $370 \mathrm{Km}$ in Pakistan). It enters India from East of Shipki La (altitude $-3,048 \mathrm{~m}$, above msl) after traversing a length of about $320 \mathrm{~km}$ (200 miles) in the Tibetan province of Nari Khorsam, through a narrow gorge in the Kinnaur district of Himachal Pradesh and flows in southwesterly direction. The river is supported by a number of mighty tributaries on either side. Main tributaries are Spiti, Baspa and Gambhar at Khab, Karchham and Kangri at an elevation of 2,600, 1,750 and $450 \mathrm{~m}$ above msl respectively. Near Rampur, it crosses the Dhauladhar range and then traverses through a series of successive Shiwalik ranges. Before leaving the Himachal Pradesh, it cuts a gorge in Naina Devi Dhar and mingles with the water of Govind Sagar Lake. It enters the plains of Punjab near Bhakra where Asia's one of the highest gravity multipurpose dam (Capacity to generate electricity $-1,325$ MW and height - $740 \mathrm{ft} / 225.55 \mathrm{~m}$ ) has been constructed. It finally drains into the main Indus River in Pakistan. 


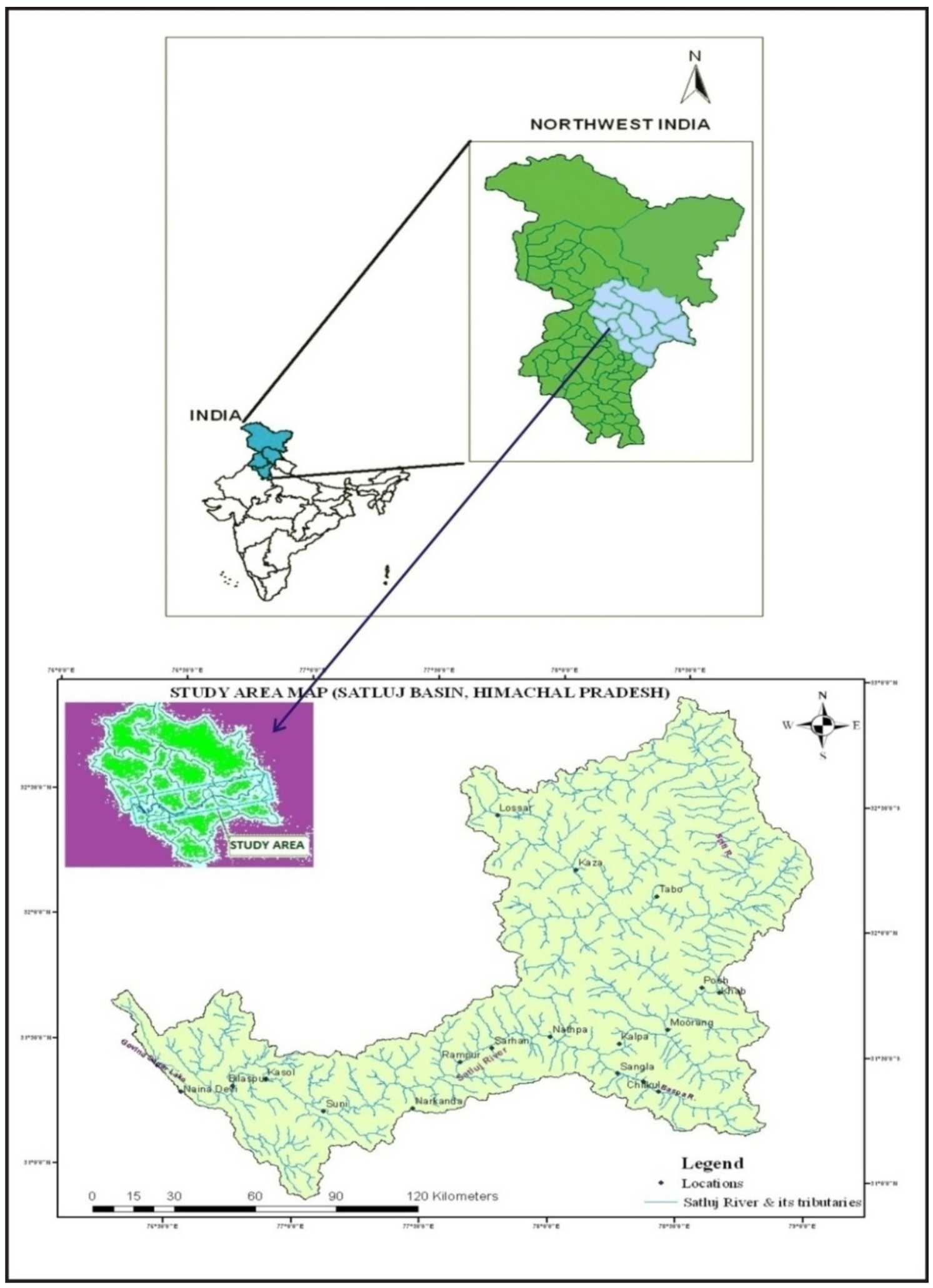

Figure 1. Schematic showing the study area map of Satluj River Basin upto Bhakra Dam, Himachal Pradesh.

Based on the amount of annual precipitation and the variation in temperature, the study area, from North to South, has been divided into three broad climatic zones (Figure 2). Each zone is characterised by its own peculiarities of climatic factors, geomorphic and topographic features (Gupta et al., 1994; Bartarya et al., 1996):

Semi-arid to arid temperate zone (Cold desert) - This zone lies in the upper Satluj Valley, upstream from Morang. Towards North of Morang, the cold desert conditions prevail which are characterised 
by very low monsoonal precipitation, high speed of cold winds and the precipitation generally occurs in the form of snowfall during winter season.

Sub-humid to humid temperate zone - This zone covers the middle Satluj Valley between the Wangtu and Morang. It is the transitional zone which receives low rainfall during the monsoon period and moderate to heavy snowfall in the higher reaches during winter.

Wet temperate or Monsoonal zone - It lies in the lower Satluj Valley downstream of Wangtu. This zone is under the great influence of monsoonal winds and receives heavy rainfall during rainy season from mid June to mid September.

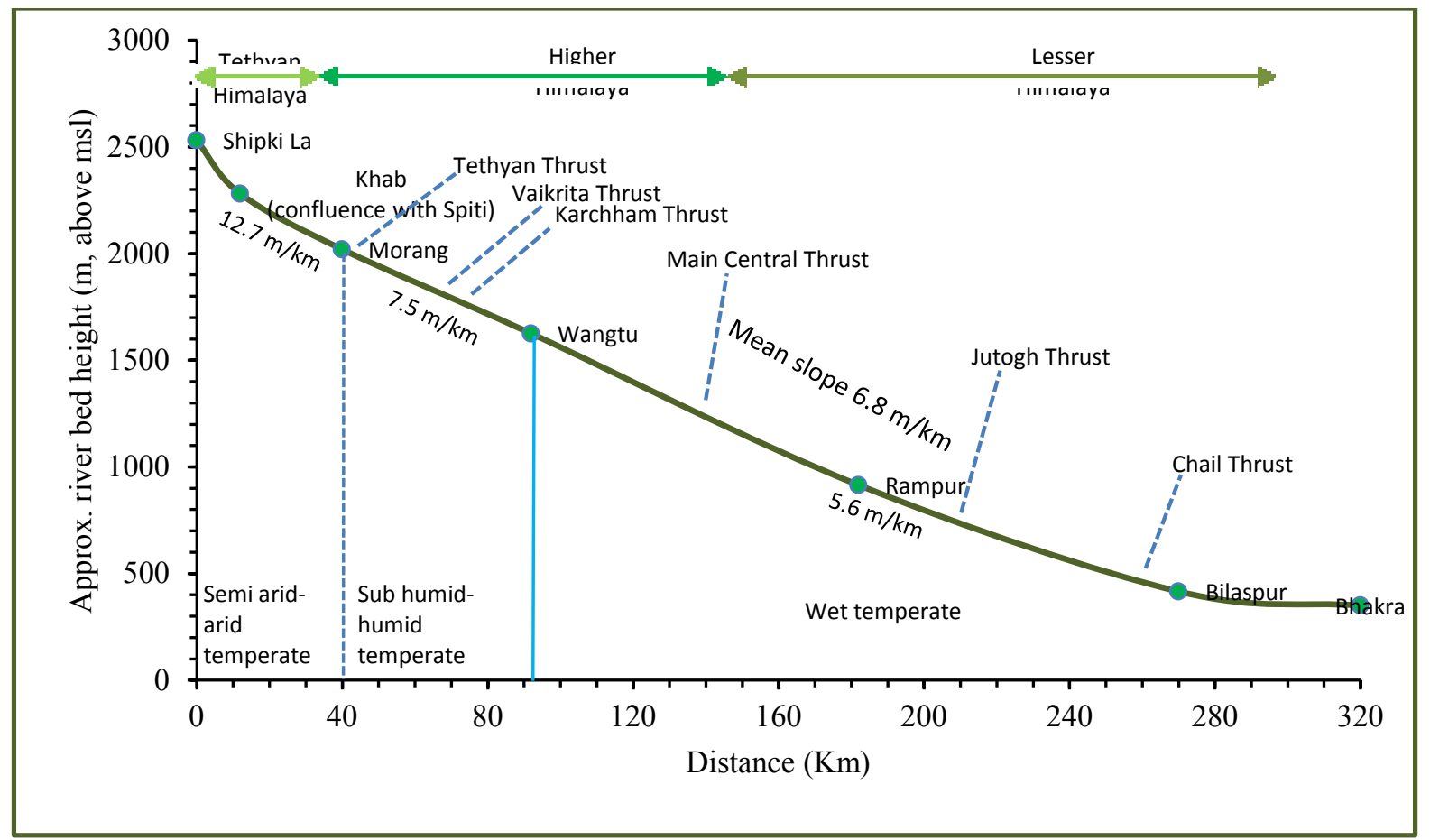

Figure 2. Longitudinal profile of Satluj River from Shipki La to Bhakra Dam. Three climatic zones are demarcated along with the major thrusts.

The fall of Satluj from its source to the plain areas is very uniform. A gross fall of $2,180 \mathrm{~m}$ is available in the river bed from Shipki La to Bhakra in a length of about $320 \mathrm{Km}$ (Figure 2). The altitude in the study area increases from West to East and South to North. Based on broad climatic conditions, the Satluj River Basin has following four seasons: Winter (December to March), Premonsoon (April to June), Monsoon (July to September), Post-monsoon (October, November).

\section{MATERIALS AND METHODS}

The geo-referenced ASTER DEM (30 m resolution) was used for studying the distribution of precipitation with elevation in Satluj River Basin (Figure 3) which was procured from NIH, Roorkee. The elevation values at each gauging station were extracted from DEM. 


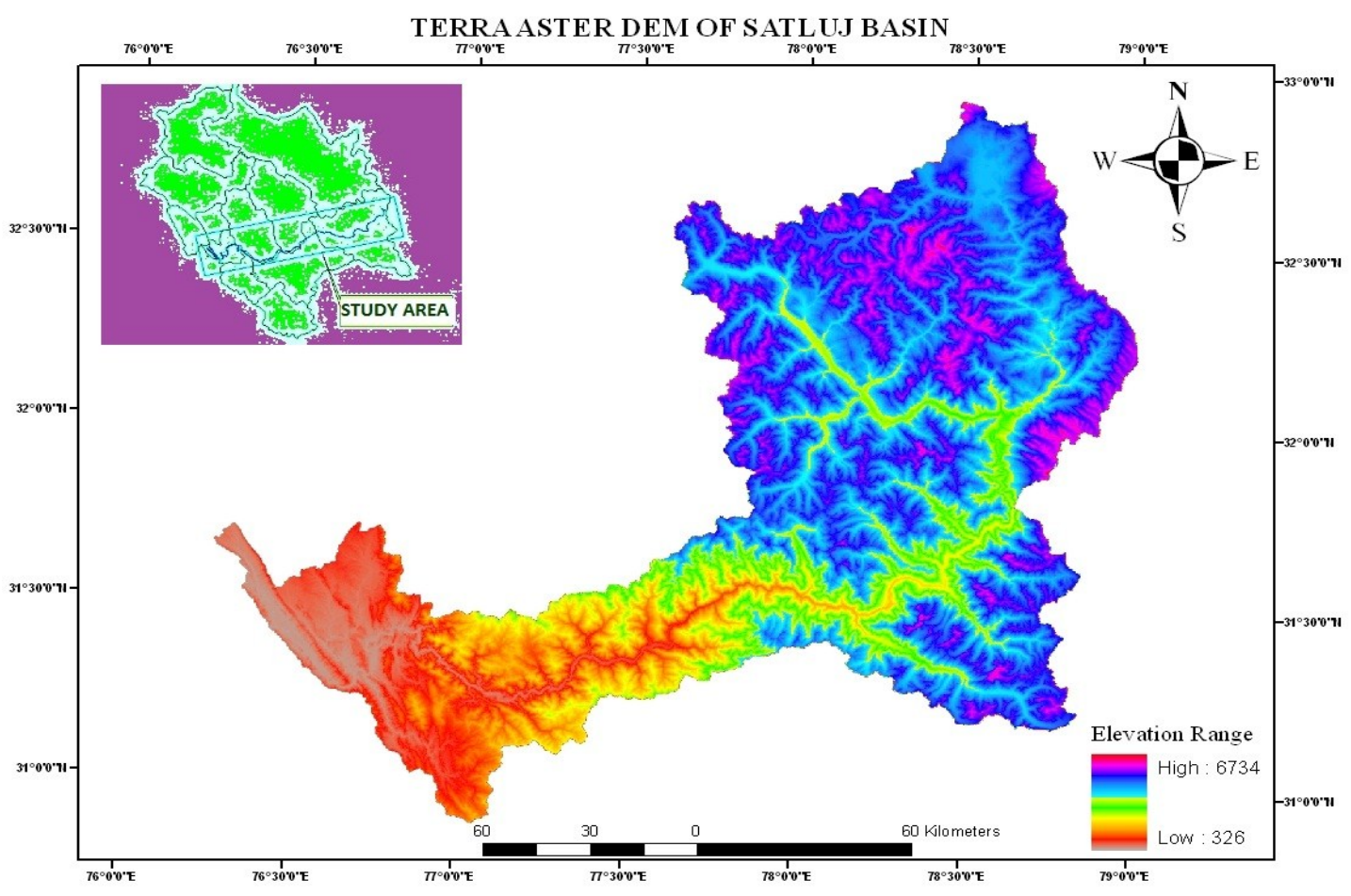

Figure 3. Digital Elevation Model (DEM) of Indian part of Satluj River Basin (up to Bhakra Dam).

The number and distribution of control points can greatly influence the accuracy of spatial interpolation of precipitation with elevation. Rainfall data of 15 locations distributed irregularly throughout the basin (Figure 4) for the period of 1986-2010 as shown in table 1 were used to create continuous surface for rainfall. These values were digitally encoded into a GIS database using ArcGIS 9.3 software by spatially joining shape file of study area to the desired rainfall data (provided as *.txt file).

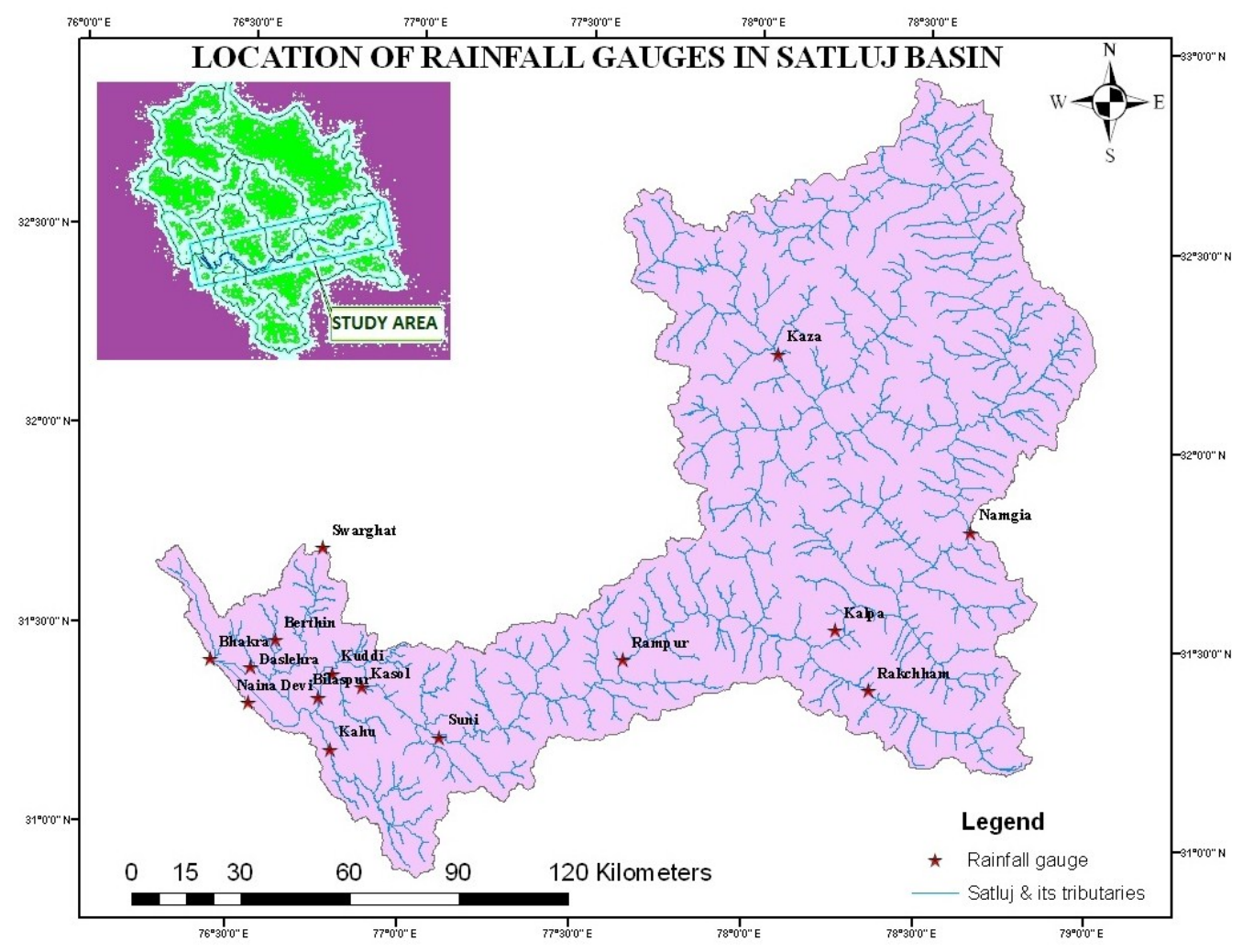

Figure 4. Location of rainfall gauge stations in Satluj River Basin. 
Table 1. Location and elevation of rainfall gauge stations in Satluj River Basin with average of cumulative rainfall (1986-2010).

\begin{tabular}{|l|l|l|l|l|}
\hline S. No. & $\begin{array}{l}\text { Gauge } \\
\text { stations }\end{array}$ & Latitude and longitude & Elevation $(\mathrm{m})$ & $\begin{array}{l}\text { Average of cumulative } \\
\text { rainfall (mm), 1986-2010 }\end{array}$ \\
\hline 1. & Rampur & $31^{\circ} 27^{\prime} 15^{\prime \prime} \& 77^{\circ} 38^{\prime} 40^{\prime \prime}$ & 1302 & 4037.10 \\
\hline 2. & Suni & $31^{\circ} 4^{\prime} 15^{\prime \prime} \& 77^{\circ} 06^{\prime} 30^{\prime \prime}$ & 843 & 5063.28 \\
\hline 3. & Kasol & $31^{\circ} 21^{\prime} 25^{\prime \prime} \& 76^{\circ} 52^{\prime} 42^{\prime \prime}$ & 809 & 6537.08 \\
\hline 4. & Bhakra & $31^{\circ} 24^{\prime} 53^{\prime \prime} \& 76^{\circ} 25^{\prime} 59^{\prime \prime}$ & 588 & 8024.49 \\
\hline 5. & Namgia & $31^{\circ} 48^{\prime} 11^{\prime \prime} \& 78^{\circ} 38^{\prime} 34^{\prime \prime}$ & 3083 & 2002.35 \\
\hline 6. & Rakchham & $31^{\circ} 23^{\prime} 30^{\prime \prime} \& 78^{\circ} 21^{\prime} 20^{\prime \prime}$ & 3282 & 537.90 \\
\hline 7. & Kalpa & $31^{\circ} 32^{\prime} 25^{\prime \prime} \& 78^{\circ} 15^{\prime} 30^{\prime \prime}$ & 2633 & 582.04 \\
\hline 8. & Kaza & $32^{\circ} 13^{\prime} 30^{\prime \prime} \& 78^{\circ} 04^{\prime} 20^{\prime \prime}$ & 3756 & 1298.94 \\
\hline 9. & Swarghat & $31^{\circ} 42^{\prime} 23^{\prime \prime} \& 76^{\circ} 44^{\prime} 58^{\prime \prime}$ & 1314 & 5751.99 \\
\hline 10. & Bilaspur & $31^{\circ} 20^{\prime} 00^{\prime \prime} \& 76^{\circ} 45^{\prime} 00^{\prime \prime}$ & 481 & 6578.79 \\
\hline 11. & Kahu & $31^{\circ} 12^{\prime} 13^{\prime \prime} \& 76^{\circ} 47^{\prime} 15^{\prime \prime}$ & 651 & 6605.30 \\
\hline 12. & Berthin & $31^{\circ} 28^{\prime} 15^{\prime \prime} \& 76^{\circ} 37^{\prime} 20^{\prime \prime}$ & 656 & 5825.64 \\
\hline 13. & Naina & $31^{\circ} 19^{\prime} 10^{\prime \prime} \& 76^{\circ} 32^{\prime} 16^{\prime \prime}$ & 739 & 6794.23 \\
\hline 14. & Kuddi & $31^{\circ} 23^{\prime} 23^{\prime \prime} \& 76^{\circ} 47^{\prime} 25^{\prime \prime}$ & 659 & 6794.23 \\
\hline 15. & Daslehra & $31^{\circ} 24^{\prime} 00^{\prime \prime} \& 76^{\circ} 33^{\prime} 00^{\prime \prime}$ & 801 & 6362.13 \\
\hline
\end{tabular}

In the mountainous regions, there is difficulty in accurate representation of spatio-temporal variability of precipitation. So, the selection of spatial interpolation method is especially important in the region where data collection is sparse and variable changes are significant over short spatial distances. Several interpolation approaches are available in geographical information system (GIS) to meet the requirements of spatial distribution of precipitation with elevation. These are deterministic (Inverse Distance Weighted and Spline) and geo-statistical (Kriging) interpolation methods to estimate the values in between sampling locations.

Spline is a deterministic, locally stochastic interpolation technique that represents twodimensional curves on three dimensional surfaces (Eckstein 1989; Hutchinson and Gessler 1994). It can be considered as fitting a rubber-sheeted surface through the known points using a mathematical function that minimises overall surface curvature, resulting in a smooth surface. It is approximately a piecewise cubic polynomial that is continuous and has continuous first and second derivatives (Burrough and McDonnel 1998). In ArcGIS, the Spline interpolation is a Radial Basis Function (RBF). The RBFs are used for calculating smooth surfaces from a large number of data points. The Spline function produces good results for gently varying phenomena such as rainfall. The most useful RBF which provides good accurate approximations is Thin Plate Spline.

Thin-plate smoothing spline interpolation was developed primarily by Wahba and Wendelberger (1980), and its application to climate analysis was implemented by Hutchinson (1993). The method provides accurate estimates of climate by allowing for spatially varying dependence on topography and is able to provide a direct estimation of interpolation error and efficient diagnosis of data errors (Hutchinson and Gessler, 1994). It can be effectively used to interpolate spatial rainfalls more accurately than the conventional techniques, especially for mountainous areas. It can generate meteorological surfaces using a trivariate function of latitude, 
longitude, and elevation of gauge stations. It was proved to be a robust technique for dealing with noisy multivariate data (Taesombat and Sriwongsitanon 2009). Although rainfall is gauged at points over typically sparse networks, for many environmental studies, it is useful to interpolate these records as a continuous surface, represented by isohyets.

It is also referred to as the basic minimum curvature technique or thin plate interpolation as it possesses two main features: (a) the surface must pass exactly through the data points, and (b) the surface must have minimum curvature. Price (1999) revealed that the TPS technique produced better results for elevation dependent spatial interpolation of monthly climatic data from sparse network of weather stations. An underlying statistical model for a partial thin-plate spline with two independent position variables (latitude and longitude) and linear dependence on elevation is given as follows:

$$
q_{i}=f\left(x_{i}, y_{i}\right)+\sum_{j=1}^{p} \beta_{j} \psi_{i j}+\varepsilon_{i} \quad(i=1, \ldots \ldots, n)
$$

Where, $q_{i}$ is the dependent climate variable at position $\left(x_{i}, y_{i}\right), x_{i}, y_{i}$ are the independent variables of the $\left(x_{i}, y_{i}\right)$ position of the $\mathrm{i}^{\text {th }}$ observational data, $\psi_{i j}$ is the set of covariates $(j=1, \ldots, p)$ at position $\left(x_{i}, y_{i}\right), f\left(x_{i}, y_{i}\right)$ is the unknown smoothing function at position $\left(x_{i}, y_{i}\right), \beta_{j}$ is the set of unknown weighing parameters, $\varepsilon_{i}$ is the independent random error with zero mean and variance $d_{i} \sigma^{2}$, and $d_{i}$ is the known local relative standard deviation as weights.

The term $\beta_{j} \psi_{i j}$ is a linear function based on elevation $\left(\psi_{i j}\right)$, when it is applied to rainfall correction. The smoothing function $f\left(x_{i}, y_{i}\right)$ and the parameter $\beta_{j}$ are estimated by minimising the functional errors.

$$
\sum_{i=1}^{n}\left[\left(q_{i}-f\left(x_{i}, y_{i}\right)-\sum_{j=1}^{p} \beta_{j} \psi_{i j}\right) / d_{i}\right]^{2}+\lambda J_{m}(f)
$$

where $n$ is the number of observational points of the dependent climatic variable, $J_{m}(f)$ is a measure of the smoothness of $f$ defined in terms of $m^{\text {th }}$ order derivatives of $f$, and $\lambda$ is a positive smoothing parameter, also called the Lagrange multiplier.

\section{RESULTS AND DISCUSSION}

The topography in the mountainous areas influences the precipitation due to high relief and different orientations. The Satluj River Basin experiences very uneven and unsystematic precipitation distribution with drastic variation in relief. Such effects can be observed from the rainfall distribution as shown in the following figures: 


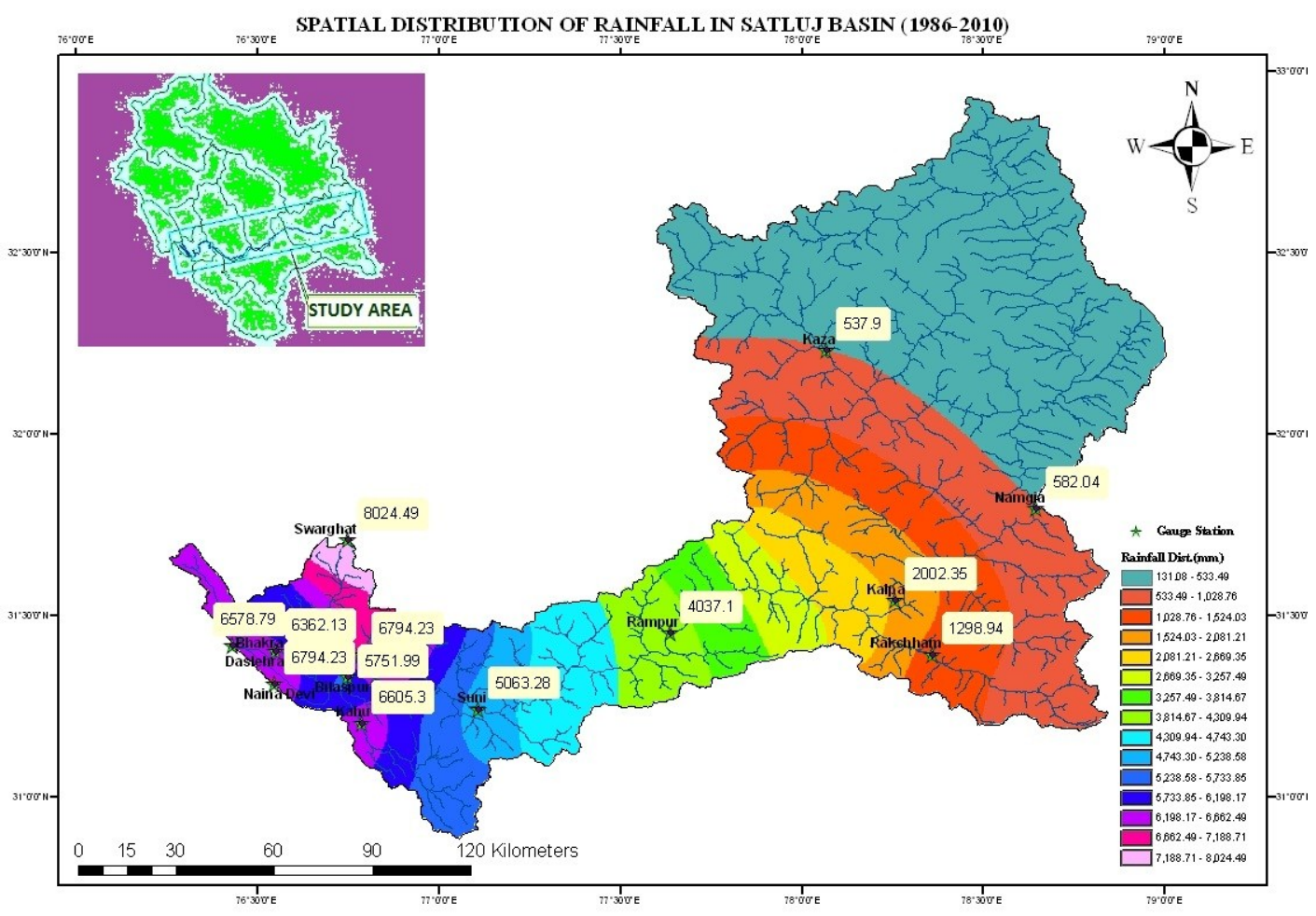

Figure 5. Spatial distribution of rainfall in Satluj River Basin (1986-2010).

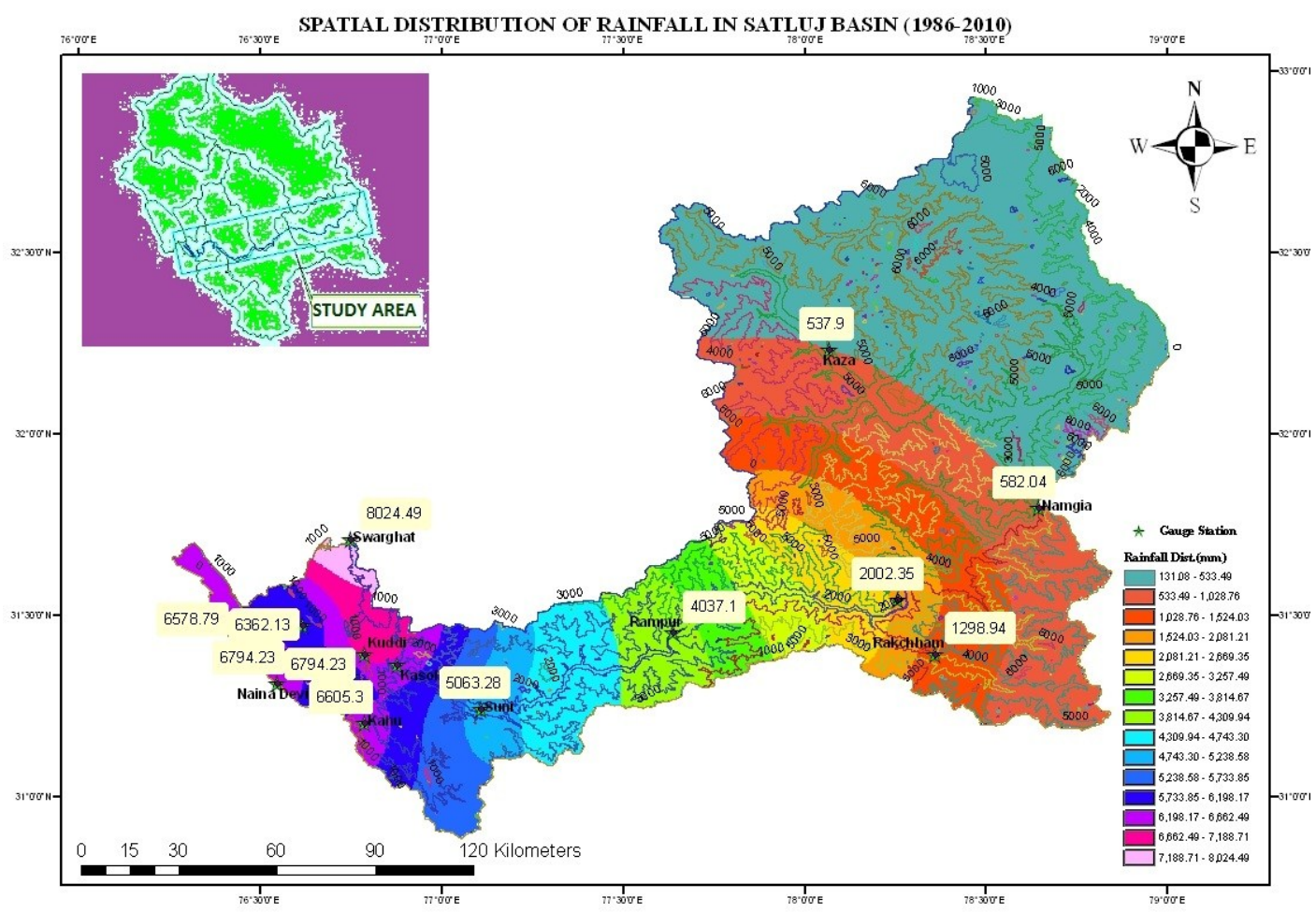

Figure 6. Spatial distribution of rainfall with elevation in Satluj River Basin (1986-2010).

Figure 5 and 6 show the spatial distribution of rainfall (average of cumulative sum of individual gauge stations) from 1986-2010, with drainage and contours respectively. Changes of spatial distribution of precipitation with elevation show a distinct shift. It reveals strong gradient, with lower values corresponding to higher elevations and higher values corresponding to lower elevations. Annual average of cumulative sum of rainfall decreases from the outer to greater Himalayas in the basin. As one moves upward, the precipitation decreases in the form of rainfall due to reduction in moisture content. From Bhakra Dam $(6578.79 \mathrm{~mm})$ to Rampur $(4037.10 \mathrm{~mm})$, 
there is continuous variation in rainfall with increase in altitude. But beyond Rampur, variation is very high. Swarghat $(8024.49 \mathrm{~mm})$ shows exceptional rainfall, may be due to position of mountains and their orographic effects. Maximum rainfall was observed in the lower Himalayas i.e. Shiwalik range. Negligible rainfall was observed beyond Kaza $(537.90 \mathrm{~mm})$, above the elevation of around $3756 \mathrm{~m}$.

From the above discussion, it was observed that the extrapolation of rainfall data from the given gauge stations, spread over the Saltuj River Basin has unsystematic distribution with fluctuational behaviour. The average of cumulative sum of rainfall at individual gauge stations in the range of 25 years (1986-2010) varies from 537.90 to $8024.49 \mathrm{~mm}$. The distribution of rainfall in the study area shows that the lower reaches of the river experiences very heavy rainfall. The general trend of rainfall exhibits that the lower and middle parts experience good rainfall whereas the upper part experiences less rainfall. Such high variation in the rainfall is a compound effect of several factors, such as the height of the mountain barrier, the strength of moisture bearing air currents, the moisture content of winds and the orientation of the mountain range with respect to the prevailing wind direction apart from the effect of climate change. Even various studies found that the change in rainfall phenomenon under the influence of climate change shows the shifting of climatic zones towards the upstream of the river.

\section{CONCLUSIONS}

The distribution of precipitation with elevation was critically viewed in light of the existing gauge stations, distributed over the basin. It was concluded that rainfall pattern was uneven and unsystematic which varies with altitude of mountains. The distribution reveals strong gradient, with lower values of rainfall corresponding to higher elevations and higher values corresponding to lower elevations. The average rainfall depth at each gauge station over the water budget period of 25 years shows different behaviour which may be due to change in climatic conditions apart from other physiographic factors. The spatial and temporal distribution of rainfall pattern is important for analysis, planning and management of water resources.

\section{Acknowledgements}

Authors are thankful to Indian Council of Medical Research (ICMR) and University Grant Commission (UGC), New Delhi for providing financial assistance in the form of research fellowship. National Institute of Hydrology (NIH), Roorkee is greatly acknowledged for providing requisite research facilities, cooperation and precious support.

\section{References}

[1] B. Bacchi, N.T. Kottegoda (1995) Identification and calibration of spatial correlation patterns of rainfall: Journal of Hydrology, 165(1-4): 311-348.

[2] S.K. Bartarya, N.S. Virdi, M.P. Sah (1996) Landslide hazards: Some case studies from the Satluj Valley, Himachal Pradesh: Himalayan Geology, 17: 193-207.

[3] A. Basistha, D.S. Arya, N.K. Goel (2008) Spatial distribution of rainfall in Indian Himalayas A case study of Uttarakhand Region: Water Resources Management, 22: 1325-1346.

[4] P.A. Burrough, R.A. McDonnel (1998) Principles of geographical information systems: Oxford University Press, New York.

[5] F.C. Collins, P.V. Bolstad (1996) A comparison of spatial interpolation techniques in temperature estimation. In: Proceedings of the Third International Conference/Workshop on Integrating GIS and Environmental Modeling, Santa Fe, New Mexico, January 21-25. National Center for Geographic Information Analysis (NCGIA), Santa Barbara, California. 
[6] O.N. Dhar, PR Rakhecha (1981) The effect of elevation on monsoon rainfall distribution in the Central Himalayas, Proc. International Symposium on Monsoon Dynamics: Cambridge University Press, pp. 253-260.

[7] B.A. Eckstein (1989) Evaluation of spline and weighted average interpolation algorithms: Computational Geosciences, 15: 79-94.

[8] P.K. Garg (1991) Development of a catchment scale erosion model for semiarid environment and its implementation through remote sensing: Ph.D. Thesis, University of Bristol, UK.

[9] P. Goovaerts (2000) Geostatistical approaches for incorporating elevation into the spatial interpolation of rainfall: Journal of Hydrology, 228: 113-29.

[10] L. Guenni, M.F. Hutchinson (1998) Spatial interpolation of the parameters of a rainfall model from ground based data: Journal of Hydrology, 212-213: 335-347.

[11] V. Gupta, M.P. Sah (2008) Impacts of the Trans-Himalayan Landslide Lake Outburst Flood (LLOF) in the Satluj catchment, Himachal Pradesh, India: Natural Hazards, 45: 379-390.

[12] V. Gupta, M.P. Sah, N.S. Virdi, S.K. Bartarya (1994) Landslide hazard zonation in the Upper Satluj Valley, District. Kinnaur, Himachal Pradesh: Journal of Himalayan Geology, 4(1): 81-93.

[13] K. Higuchi, Y. Ageta, T. Yasunari, J. Inoue (1982) Characteristics of precipitation during monsoon season in high mountain areas of the Nepal Himalayas: Hydrological Aspects of Alpine and High Mountain Areas, IAHS, 138: 21-30.

[14] S.A. Hill (1881) The meteorology of North-West Himalaya: Indian Meteorological Memoir, I(VI): 377- 429.

[15] M.F. Hutchinson (1993) On thin plate smoothing splines and kriging: Computer Science Statistics, 25: 55-62.

[16] M.F. Hutchinson (1998) Interpolation of rainfall data with thin plate smoothing splines, Part I: Two dimensional smoothing of data with short range co-relation: Journal of Geographic Information and Decision Analysis, 2: 152-167.

[17] M.F. Hutchinson (1998) Interpolation of rainfall data with thin plate smoothing splines, Part II: Analysis of topographic dependence: Journal of Geographic Information and Decision Analysis, 2: $168-185$.

[18] M.F. Hutchinson, P.E. Gessler (1994) Splines - more than just a smooth interpolator: Geoderma, 62: 45-67.

[19] I.P.C.C. (2001a) Climate change 2001: Synthesis Report, In: (eds. Watson et al.), Intergovernmental Panel on Climate Change: Cambridge University Press, Cambridge, UK and New York, USA, pp. 398.

[20] I.D. Moore, P.E. Gessler, G.A. Nielson (1993) Soil attribute prediction using terrain analysis: Soil Science Society of America Journal, 57: 443-452.

[21] D.T. Price, D.W. McKenney, I.A. Nalder, M.F. Hutchinson, J.L. Kesteven JL (1999) A comparison of two statistical methods for spatial interpolation of Canadian monthly mean climate data: Agricultural and Forest Meteorology, 101: 81-94.

[22] Schadler, Bruno (2004) Climate change issues and adaptation strategies in a mountainous region: a case study of Switzerland, Proceedings of the OECD Global Forum on Sustainable Development: Development and Climate Change, pp. 9.

[23] P. Singh, N. Kumar (1997) Impact assessment of climate change on the hydrological response of a snow and glacier melt runoff dominated Himalayan River: Journal of Hydrology, 193: 316350 . 
[24] P. Singh, N. Kumar (1997b) Effect of orography on precipitation in the western Himalayan region: Journal of Hydrology, 199: 183-206.

[25] P. Singh, K.S. Ramasastri, N. Kumar (1995), Topographical Influence on precipitation distribution in different ranges of Western Himalayas: Nordic Hydrology, 26: 259-284.

[26] W. Taesombat, N. Sriwongsitanon (2009) Areal rainfall estimation using spatial interpolation techniques: Science Asia, 35: 268-275.

[27] S. Taher, A. Alshaikh (1998) Spatial analysis of rainfall in Southwest of Saudi Arabia using GIS: Nordic Hydrology, 29 (2): 91-104.

[28] G. Wahba, J. Wendelberger (1980) Some new mathematical methods for variational obj-ective analysis using splines and cross-validation: Monthly Weather Review, 108: 1122-1145. 